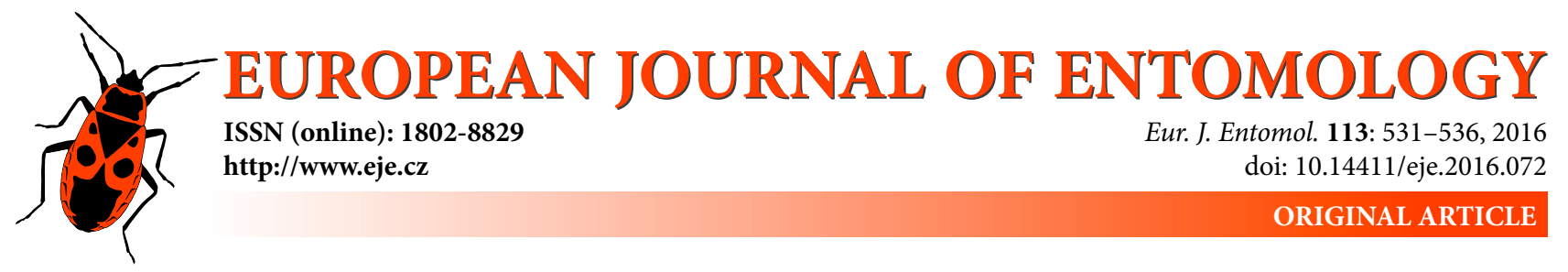

\title{
Comparative efficiency of traps for horse fly (Diptera: Tabanidae) survey in riparian oak-ash forests in Danube floodplain
}

\author{
Alma MIKUŠKA ${ }^{1}$, Selma MLINARIĆ ${ }^{1}$, LidiJA BEGOVIĆ ${ }^{1}$ and ERIN CURRAN ${ }^{2}$ \\ ${ }^{1}$ Department of Biology, Josip Juraj Strossmayer University of Osijek, Ulica cara Hadrijana 8/A, HR-31000 Osijek, Croatia; \\ e-mails: amikuska@biologija.unios.hr, smlinaric@biologija.unios.hr, lbegovic@biologija.unios.hr \\ ${ }^{2}$ Computer and Information Sciences Department, University of St. Thomas, 2115 Summit Ave., St. Paul, MN 55105, USA; \\ e-mail: ecurran@stthomas.edu
}

Key words. Diptera, Tabanidae, horse flies, Box trap, Nzi trap, Canopy trap, catching efficiency

\begin{abstract}
The objective of this work was to evaluate the relative trap efficiency of the three modified traps baited with 1-octen-3-ol as attractant, Box, Nzi and Canopy, for horse fly (Tabanidae) survey. Nine traps (three traps per trap type) were tested in $3 \times 3$ Latin square designs during summer 2011 in riparian oak-ash forests in the Danube floodplain of Croatia. Overall, the traps caught 1,986 specimens of 11 horse flies species during the study period. The most abundant species caught was Tabanus bromius (58\%), followed by Tabanus tergestinus (21\%), Tabanus maculicornis (16\%), Tabanus sudeticus (2\%), Atylotus loewianus (1\%) and Tabanus autumnalis (1\%). Both the Box traps and the Nzi traps had significantly greater catch efficiencies than the Canopy traps $\left(\beta_{\text {box }}=2.47, X^{2}=65.48, d f=1, P<0.001\right.$ and $\beta_{n z i}=1.54, X^{2}=25.12, d f=1, P<0.001$, respectively). Nzi traps had a catch rate 4.65 (95\% Cl: $2.55,8.48)$ times greater than Canopy traps and Box traps had a catch rate $11.77(95 \%$ Cl: 6.48, 21.39) times greater than Canopy traps. Based on Shannon-Wiener diversity indices Nzi traps were better suited for diversity survey and had higher $\left(H^{\prime}=1.33\right)$ indices than Box $\left(H^{\prime}=1.08\right)$ or Canopy traps $\left(H^{\prime}=1.00\right)$.
\end{abstract}

\section{INTRODUCTION}

Horse flies (Tabanidae) are part of the Dipteran family comprising over 4,400 species known worldwide (Roskov et al., 2015). The presence of water, hosts, and forests are primary and required conditions for the occurrence of horse flies (Chvála et al., 1997). In dry areas and steppes without trees, or even along large rivers that are not fringed with forests and other vegetation, horse flies are mostly absent (Chvála et al., 1997). However, under specific conditions they can occur in larger numbers in semi-arid steppes (Baldacchino et al., 2013).

Host-seeking females are considered to be major pests of ungulates world-wide. Female horse flies feed on domestic and wild animals (Baldacchino et al., 2014b) and are mechanical vectors of different pathogens, such us the equine infectious anemia virus and Besnoitia besnoiti, between the animals (Desquesnes et al., 2009; Votýpka et al., 2015).

Horse flies are generally difficult to control and currently there are no adequate control measures for reducing their populations (Barros \& Foil, 2007). Traps are designed to attract targeted insects using sensory cues and they are practical tools for vector surveillance. However, traps have been only occasionally tested for control measures (Baldacchino et al., 2014a). Control of horse flies must be based on protective actions against adults, rather than larvae (Foil
\& Hogsette, 1994). Trapping devices for adult horse flies are based on flight interception or attraction using a visual stimulus and/or a natural or synthetic odour. Recently, traps based on the attraction of horse flies to horizontallypolarized light have been developed (Horváth et al., 2008; Blahó et al., 2012). Odour-baited sticky boards are traps based on attraction (Hall et al., 1998) and traps with electric grids are based on flight interception (Muzari et al., 2010) or may be associated with a visual or odour attractant (Krčmar et al., 2014). An optimal survey trap for all horse flies species is difficult to achieve (Gibson \& Torr, 1999) because different trap types may capture different numbers of individuals and species (Mihok et al., 2006; Krčmar \& Rupnik Poklukar, 2011). Very few studies measuring trap efficiency with horse flies have been completed (Mihok et al., 2006; Mihok \& Carslon 2007; Van Hennekeler et al., 2008; Krčmar et al., 2014). Nzi, Box and Canopy traps have been used for catching horse flies in different field studies (Krčmar et al., 2006, 2010, 2014; Baldacchino et al., 2013), but a comparison and evaluation of trap efficiency has never been tested.

The present study aimed to evaluate the relative trapping efficiency of modified designs of Nzi, Box and Canopy traps for horse fly survey. Trapping efficiency was defined as the number of horse flies caught in a given time period 

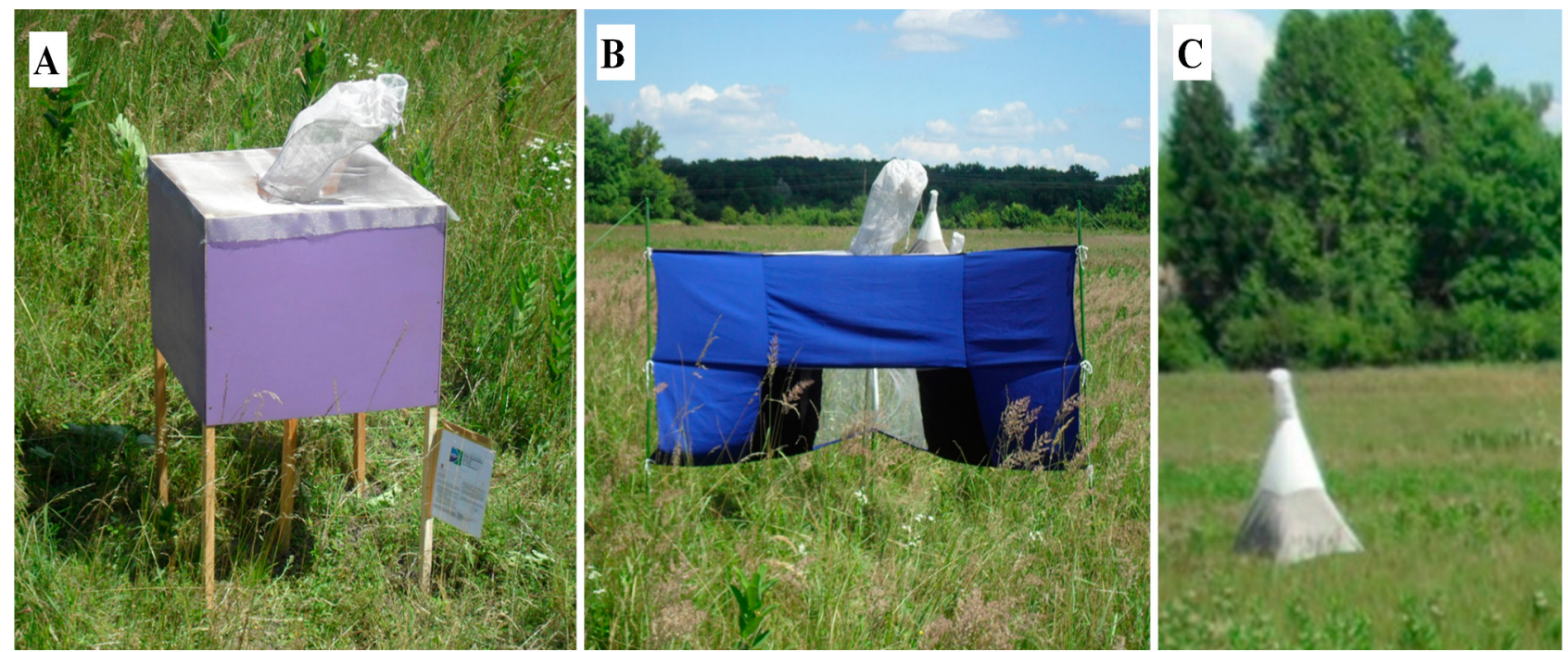

Fig. 1. Modified Box (A), Nzi (B) and Canopy (C) at study site.

(trap/day). The aim of this study was to evaluate the impact of trap design and construction on trapping efficiency, rather than to evaluate horse fly attraction to visual stimuli such as trap colour.

\section{MATERIALS AND METHODS}

\section{Study site and traps}

The study was carried out in riparian oak-ash forests in the Danube floodplain of Croatia $\left(45^{\circ} 41^{\prime} 55.59^{\prime \prime} \mathrm{S}, 18^{\circ} 49^{\prime} 20.74^{\prime \prime} \mathrm{E}\right)$ in Europe. The area has a typical continental climate with wide annual fluctuations of air temperatures and precipitation, as well as four distinctive seasons. The average annual air temperature is $10.5^{\circ} \mathrm{C}$ (with a maximum temperature of $39^{\circ} \mathrm{C}$ in July). The average annual precipitation is $687 \mathrm{~mm}$ with a peak during May-June (data were provided by the Croatian Meteorological and Hydrological Service). Ecological studies have shown that horse flies are most active at pasture-forest ecotone near their developmental, host-seeking and resting sites (Baldacchino et al., 2013) and so traps were placed on the pasture at $60 \mathrm{~m}$ distance and parallel to the forest edge.

Modified Box traps consisted of $80 \times 80 \times 60 \mathrm{~cm}$ four-sided plywood boxes, open underneath with a metal insect screen roof as described by Hansens \& Race (2011). The opening of the trap was set $50 \mathrm{~cm}$ above the ground. The collectors on these traps were modified and a $20 \mathrm{~cm}$ wide opening was cut in the center of the screen roof, rather than in the cones. Removable collecting caps made from polyester mosquito mesh (the same size as those on canopy and Nzi traps) were used. The Box traps were painted outside with a violet paint while the inner side of the box was left unpainted (Fig. 1A). The painting of the traps and the quantitative assessment of colours was performed according to the methods described in Krčmar et al. (2014).

Modified Nzi traps were $1 \mathrm{~m}$ cloth triangular traps constructed as described by Mihok (2007). The traps were made from black and blue cotton/polyester (65/35\%) fabric (Tex Ingro S.R.L. Italy). The blue fabric had peak wavelengths at $491 \mathrm{~nm}$, as recommended by Mihok (2007). The modification to the original design included an opening, $20 \mathrm{~cm}$ wide, at the top of the trap. A removable collecting cap, the same size as those on canopy traps and made from polyester mosquito mesh, was also used. The traps were set on the ground with the entrance facing the forest edge (Fig. 1B).
The tent-like Canopy traps were constructed according to the design of Hribar et al. (1991). Four-sided pyramidal structures, $250 \mathrm{~cm}$ tall with $120 \mathrm{~cm}$ wide openings, were made from black and white cotton fabric. The collecting caps were made from polyester mosquito mesh, $20 \mathrm{~cm}$ wide and $35 \mathrm{~cm}$ high, and were placed on the top of the trap (Fig. 1C). The entrance to the Canopy trap was $50 \mathrm{~cm}$ from the ground.

To improve collection performance of the traps, 1-octen-3-ol (98\% pure; Sigma-Aldrich Chemie GmbH, Germany) was used as an attractant. Plastic vials with $4 \mathrm{~mL}$ of 1 -octen-3-ol and $5 \mathrm{~cm}$ long cotton were attached to wooden sticks inside all of the traps and placed $30 \mathrm{~cm}$ below the top of traps. The attractant evaporation was measured at the study site over $24 \mathrm{~h}$ (with a daily mean temperature of $20.4{ }^{\circ} \mathrm{C}$ and relative moisture of $88 \%$ without the wind) to test the possibility that 1-octen-3-ol would evaporate differently, depending on trap type. The evaporation of the attractant was up to $1 \mathrm{~mL} /$ day in every trap type. Evaporation of 1-octen3-ol in Box traps was faster than in Nzi or Canopy traps. Consequently, 1-octen-3-ol was added daily, up to the amount of $4 \mathrm{~mL}$, to ensure that there was a sufficient supply of attractant during throughout the trapping time.

\section{Study design}

A total of 24 sampling days, eight continuous days per month, were conducted between June and August 2011. The trapping period was between 8:00 am and 8:00 pm each day. The experiment consisted of three $3 \times 3$ Latin square designs. Nine traps (including three traps of each type) were placed $50 \mathrm{~m}$ apart from one another. The positions of the traps were exchanged every month to nullify any possible effect of trap position on trap performance. Thus, each trap type was located at each of nine possible positions during the course of this experiment.

An area of approximately $5 \mathrm{~m}$ in diameter was cleared of grass around each trap. The collection caps were emptied every morning, and collected horse flies were preserved in $70 \%$ ethanol. The identification and the nomenclature followed Chvála et al. (1972) and Chvála (1988).

\section{Statistical analysis}

A negative binomial regression model incorporating an overdispersion parameter estimate of 1.0 was used to predict horse fly catch efficiency from the type of trap used. Negative binomial regression is an appropriate analytic strategy given the strong right skew observed in the dependent variable and the catch efficiency 
differences attributable to trap type over a defined period of data collection. To create a model of catch efficiency, the variable "trap type" was dummy coded to generate two binary predictors (Box trap and Nzi trap); canopy trap was used as the reference category. The log of the outcome variable, "total horse fly count", an indicator of catch efficiency, was modeled as a function of the two identified binary predictors and the overdispersion parameter estimate. Models were created for the overall results (utilizing data from all horse fly specimens collected) and separately for the T. bromius, T. tergestinus, and T. maculicornis species of the horse fly. Other horse fly species were present in numbers too low for such modelling.

In addition to overall tests of model significance, several additional statistical results were evaluated. Regression model coefficients $(\beta)$ were examined to understand the nature of the association between the predictor and the outcome variable. Contributions of each predictor to the model were evaluated for statistical significance using Wald $X^{2}$ test statistics. Incidence rate ratios and their $95 \%$ confidence interval limits were calculated to quantify differences between trap types in catch rates. Finally, pairwise comparisons of trap types on catch efficiencies were calculated to identify statistically significant differences between trap types regarding catch efficiency. A Bonferroni adjustment was applied to the pairwise comparison significance values to enhance protection against Type I error. All statistical analyses were performed using IBM SPSS Statistics for Windows, Ver. 20.0 (IBM Corporation, Armonk, NY).

Data on horse fly fauna from a previous study were used to assess the efficiency of different trap types for surveillance (Mikuška, 2010). During this survey, carried out from 20042009, 23 species with 12,452 individuals in total were caught by Canopy traps baited with different natural and synthetic attractants. Different trap types were compared in terms of efficiency for surveillance using Shannon-Wiener index of diversity (Krebs, 1989).

\section{RESULTS}

In total, 1,986 horse fly specimens were collected during the sampling period. Out of 11 collected species, the most abundant was T. bromius with $58 \%$ of the total catch, followed by T. tergestinus (21\%) and T. maculicornis (16\%). All other species each represented less than $2 \%$ of the total catch (Table 1). The same catching order of three most abundant species was maintained among the three trap types (Table 1). Modified Nzi traps were more efficient in catching T. sudeticus and T. autumnalis than Box and Canopy traps (Table 1).

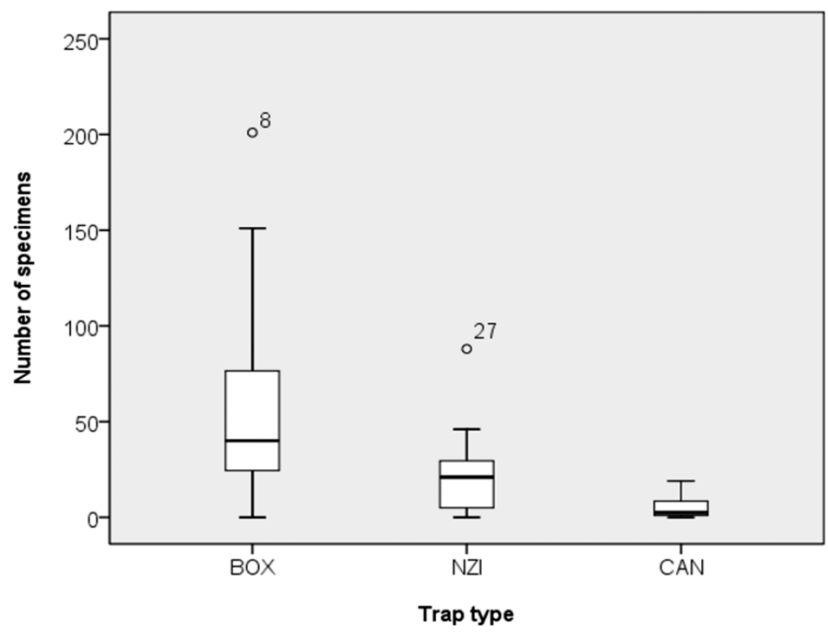

Fig. 2. Trap efficiencies (median number of horse flies/trap days) for three trap types. Numbers above the circles represent outliers, boxes represent upper and lower quartile, while whiskers represent minimum and maximum values except outliers.

The modified Box traps consistently caught more horse flies than either modified Nzi or Canopy traps (Fig. 2). The overall model predicting total horse fly count from predictors Box trap and Nzi trap is statistically significant, $X^{2}$ $=57.54, d f=2, P<0.001$. This result indicates that this model represents a statistically significant improvement in fit over a null model containing zero predictors. Parameter estimate statistics suggest that both the Box traps and the Nzi traps have significantly greater catch efficiencies than the Canopy traps $\left(\beta_{b o x}=2.47, X^{2}=65.48, d f=1, P<\right.$ 0.001 and $\beta_{n z i}=1.54, X^{2}=25.12, d f=1, P<0.001$, respectively). Incidence rate ratios suggest that for all species of horse fly included in this study, Nzi traps are expected to have a catch rate 4.65 (95\% CI: $2.55,8.48)$ times higher than Canopy traps. The Box traps are expected to have a catch rate $11.77(95 \%$ CI: $6.48,21.39)$ times greater than Canopy traps, holding all other variables in the model constant. Pairwise comparisons indicate that box traps $(\bar{x}=$ 55.92) demonstrate better catch efficiency over both Nzi traps $(\bar{x}=22.08 ; P=0.019)$ and Canopy traps $(\bar{x}=4.75$; $P<0.001)$. Moreover, Nzi traps demonstrate significantly greater catch efficiency than Canopy traps $(P=0.001)$.

Table 1. Number of species and specimens caught per each trap type during the study period.

\begin{tabular}{|c|c|c|c|c|c|c|c|c|}
\hline \multirow{2}{*}{ Species / Trap type } & \multicolumn{2}{|c|}{ Modified Box } & \multicolumn{2}{|c|}{ Modified Nzi } & \multicolumn{2}{|c|}{ Modified Canopy } & \multicolumn{2}{|c|}{ Total } \\
\hline & No: & $\%$ & No: & $\%$ & No: & $\%$ & No: & $\%$ \\
\hline Tabanus bromius L.,1758 & 817 & 61 & 254 & 48 & 80 & 70 & 1151 & 58 \\
\hline Tabanus tergestinus Egger, 1859 & 241 & 18 & 154 & 29 & 19 & 17 & 414 & 21 \\
\hline Tabanus maculicornis Zetterstrdt, 1842 & 238 & 18 & 65 & 12 & 8 & 7 & 311 & 16 \\
\hline Tabanus sudeticus Zeller, 1842 & 5 & 0.4 & 35 & 7 & - & & 40 & 2 \\
\hline Atylotus loewianus (Villeneuve, 1920) & 26 & 2 & - & & 2 & 2 & 28 & 1 \\
\hline Tabanus autumnalis L., 1761 & 10 & 0.8 & 15 & 3 & 1 & 0.9 & 26 & 1 \\
\hline Haematopota pluvialis (L., 1758) & 2 & 0.2 & 1 & 0.2 & 2 & 1.8 & 5 & 0.3 \\
\hline Hybomitra muehlfeldi (Brauer, 1880) & 1 & 0.07 & 3 & 0.6 & - & & 4 & 0.2 \\
\hline Haematopota italica Meigen, 1804 & 1 & 0.07 & 1 & 0.2 & 1 & 0.9 & 3 & 0.2 \\
\hline Hybomitra ciureai (Séguy, 1937) & 1 & 0.07 & 1 & 0.2 & 1 & 0.9 & 3 & 0.2 \\
\hline Tabanus bovinus L., 1758 & - & & 1 & 0.2 & - & & 1 & 0.05 \\
\hline Total & 1342 & & 530 & & 114 & & 1986 & \\
\hline
\end{tabular}


Table 2. Capture rates of three trap types for each species (mean \pm SD).

\begin{tabular}{|c|c|c|c|}
\hline \multirow{2}{*}{ Species } & \multicolumn{3}{|c|}{ Mean number of each species caught per trap (mean \pm SD) } \\
\hline & Modified Box trap & Modified Nzi trap & Modified Canopy trap \\
\hline T. bromius & $11( \pm 13)$ & $4( \pm 8)$ & $1( \pm 3)$ \\
\hline T. tergestinus & $3( \pm 10)$ & $2( \pm 6)$ & $0.3( \pm 0.8)$ \\
\hline T. maculicornis & $3( \pm 10)$ & $0.9( \pm 3)$ & $0.1( \pm 0.5)$ \\
\hline A. loewianus & $0.4( \pm 1)$ & - & $0.03( \pm 0.2)$ \\
\hline T. autumnalis & $0.1( \pm 0.4)$ & $0.2( \pm 0.6)$ & $0.01( \pm 0.1)$ \\
\hline T. sudeticus & $0.1( \pm 0.3)$ & $0.5( \pm 1.4)$ & - \\
\hline H. pluvialis & $0.02( \pm 0.2)$ & $0.01( \pm 0.1)$ & $0.02( \pm 0.2)$ \\
\hline H. italica & $0.01( \pm 0.1)$ & $0.01( \pm 0.1)$ & $0.01( \pm 0.1)$ \\
\hline H. ciureai & $0.01( \pm 0.1)$ & $0.01( \pm 0.1)$ & $0.01( \pm 0.1)$ \\
\hline H. muehfleldi & $0.01( \pm 0.1)$ & $0.04( \pm 0.3)$ & - \\
\hline T. bovinus & - & $0.01( \pm 0.1)$ & - \\
\hline Total & $18( \pm 39)$ & $7( \pm 16)$ & $2( \pm 4)$ \\
\hline
\end{tabular}

Capture efficiencies of three trap types for each species are presented in Table 2.

\section{Evaluation of traps for surveillance}

The fauna of the studied area consists 23 horse fly species recorded during the 2004-2009 period (Mikuška, 2010). During this study period traps have caught only 11 species in total (Box and Nzi - 10 species, Canopy -8 species) (Table 1). However, traps caught the nine most abundant species in the area. Comparing Shannon-Wiener diversity indices revealed that Nzi traps had higher $\left(H^{\prime}=\right.$ $1.33)$ indices than Box $\left(H^{\prime}=1.08\right)$ or Canopy traps $\left(H^{\prime}=\right.$ 1.00), but lower Shannon-Wiener diversity index than for the area $\left(H^{\prime}=1.50\right)$.

\section{Species-specific results}

Capture efficiencies and catch rates for three most abundant horse fly species are presented in Table 3.

(a) Tabanus bromius: Similar to the overall results, the model predicting total $T$. bromius horse fly count from predictors Box trap and Nzi trap is statistically significant, $X^{2}$ $=53.71, d f=2, P<0.001$. Pairwise comparisons indicate that Box traps $(\bar{x}=34.04)$ possess superior catch efficiency over both Nzi traps $(\bar{x}=10.58 ; P=0.005)$ and Canopy traps $(\bar{x}=3.33 ; P<0.001)$; Nzi traps also demonstrate significantly greater catch efficiency over Canopy traps $(P=$ $0.007)$ for this species.

(b) Tabanus tergestinus: The model predicting total $T$. tergestinus horse fly count from predictors Box trap and Nzi trap is statistically significant $\left(X^{2}=46.89, d f=2, P\right.$ $<0.001$ ). For this particular species of horse fly, pairwise comparisons indicate that Box traps $(\bar{x}=10.04)$ and Nzi traps $(\bar{x}=6.42)$ showed statistically similar catch efficiencies $(P=0.475)$. However, both Box traps and Nzi traps demonstrated significantly greater catch efficiencies than Canopy traps $(\bar{x}=0.79 ; P<0.001$ and $P<0.001$, respectively).

(c) Tabanus maculicornis: The model predicting total $T$. maculicornis horse fly count from predictors Box trap and Nzi trap is statistically significant, $X^{2}=69.99, d f=2, P$ $<0.001$. For this species, pairwise comparisons suggested that Box traps $(\bar{x}=9.92)$ showed significantly greater catch efficiency than both Nzi traps $(\bar{x}=2.71 ; P=0.004)$ and Canopy traps $(\bar{x}=3.33 ; P<0.001)$. Additionally, Nzi traps demonstrated significantly greater catch efficiency than canopy traps $(P=0.001)$.

\section{DISCUSSION}

Our study demonstrated that modified Box traps had higher trapping efficiency than both modified Nzi and Canopy traps using 1-octen-3-ol as attractant for the three traps. This result may be attributed to two main features of trap construction and design: trap opening size/position and attractant release rate. Box traps have a $1 \mathrm{~m}^{2}$ opening on the bottom of the trap and the trap is placed $50 \mathrm{~cm}$ above the ground; this large, accessible opening allows horse flies to enter the trap from all sides. By contrast, Nzi traps have an opening that is only half of the size $\left(0.5 \mathrm{~m}^{2}\right)$ of the Box trap opening which may limit accessibility. Furthermore, because these traps are set on the ground, the Nzi trap opening serves to intercept the flight of horse flies com-

Table 3. Catch efficiencies $(\beta)$ and catch rates for three most abundant horse fly species.

\begin{tabular}{|c|c|c|c|c|}
\hline & Species / Trap type & Tabanus bromius & Tabanus tergestinus & Tabanus maculicornis \\
\hline \multirow{2}{*}{ Catch efficiency $(\beta)$} & Box & $\begin{array}{l}2.32 \\
X^{2}=55.63 ; d f=1 \\
P<0.001\end{array}$ & $\begin{array}{l}2.54 \\
X^{2}=46.06 ; d f=1 \\
P<0.001\end{array}$ & $\begin{array}{l}3.39 \\
X^{2}=54.16 ; d f=1 \\
P<0.001\end{array}$ \\
\hline & $\mathrm{Nzi}$ & $\begin{array}{l}1.16 \\
X^{2}=13.38 ; d f=1 \\
P<0.001\end{array}$ & $\begin{array}{l}2.09 \\
X^{2}=30.74 ; d f=1 \\
P<0.001\end{array}$ & $\begin{array}{l}2.10 \\
X^{2}=19.62 ; d f=1 \\
P<0.001\end{array}$ \\
\hline \multirow{2}{*}{$\begin{array}{l}\text { Catch rate vs. } \\
\text { Canopy trap }\end{array}$} & Box & $\begin{array}{l}10.21 \\
95 \% \text { Cl: } 5.55,18.81\end{array}$ & $\begin{array}{l}12.68 \\
95 \% \text { Cl: } 6.09,26.42\end{array}$ & $\begin{array}{l}29.75 \\
95 \% \mathrm{Cl}: 12.05,73.44\end{array}$ \\
\hline & $\mathrm{Nzi}$ & $\begin{array}{l}3.18 \\
95 \% \text { Cl: } 1.71,5.90\end{array}$ & $\begin{array}{l}8.11 \\
95 \% \text { Cl: } 3.87,16.98\end{array}$ & $\begin{array}{l}8.13 \\
95 \% \text { Cl: } 3.22,20.53\end{array}$ \\
\hline
\end{tabular}

$d f$ - degrees of freedom, $\mathrm{Cl}$ - confidence interval 
ing from only one direction. Like Box traps, Canopy traps also have a large opening on the bottom $\left(120 \mathrm{~cm}^{2}\right)$, but it is diamond shaped when the trap is erected. Furthermore, the roof of a Box trap is made of a metal insects screen that provides a $1 \mathrm{~m}^{2}$ large opening where attractant can freely disperse into the surrounding area. By contrast, Canopy traps have a very small (up to $10 \mathrm{~cm}^{2}$ ) opening on top and most of the evaporated attractant is held within the tentlike structure. Indeed, in this study, Box traps had a faster rate of attractant evaporation than Nzi or Canopy traps (but not higher than $1 \mathrm{~mL} /$ day). Higher evaporation rates could lead to higher numbers of horse flies attracted to the trap and consequently to higher catch rates.

In addition to yielding higher catch rates, the robust construction of modified Box traps made them highly practical for long-term horse fly survey and monitoring. The fabric of Nzi traps was occasionally damaged by grasshoppers (Orthoptera: Acrididae) that were chewing holes in the netting of the traps. Constant maintenance was required to keep the Nzi traps operational and made their routine use in the field rather difficult. This assertion is consistent with the findings of Taylor \& Berkebile (2006). On the other hand, the modified Nzi traps were more stable than the modified Canopy traps. Morevoer, the combination of blue paint and octenol as an attractant may have made modified Nzi traps more efficient than the modified black and white Canopy traps baited with the same attractant. The relatively weak performance of the Canopy traps in the present study is consistent with the results of previous studies in North America and Australia (Mihok et al., 2006; Van Hennekeler et al., 2008).

Trap design and construction are not likely the only factors impacting the efficiency of the traps. The effects of specific materials and dye colors (Mihok \& Carlson, 2007), as well as different natural and synthetic attractants (Krčmar, 2005; Krčmar et al., 2006, 2010), have been studied. According to Egri et al. (2012), linearly polarized light attracts host-seeking females, but sensitivity for polarization of light has not been studied at the structural level of the horse fly eyes and may differ among species (Baldacchino et al., 2014a).

Traps are commonly used devices for monitoring, surveillance, and control of insect populations. Monitoring programs may have goals that are different from the evaluation of overall diversity, detection of invasive and/or endangered or red listed species, or surveying of population abundance of particular species (Dodds et al., 2015). Concerning the overall diversity of the horse fly fauna, the trap types used in this study caught less than half (10 out of 23 species, $43 \%$ ) of the possible species richness during the single study season (72 trap days for each trap type). However, all three trap types sampled the three most abundant species in accordance with previous studies (Krčmar, 2005; Krčmar et al., 2009; Mikuška, 2010). Evaluating this result on the faunal level, species not present in the catch were rare species with less than $0.31 \%$ occurrence during the 2004-2009 period (Mikuška, 2010). According to the Shannon-Wiener diversity index, this study demonstrated that Nzi traps were better suited for diversity survey than either Box traps or Canopy traps. This result could be related to the aspects of Nzi trap design that intercept the straight flight of the horse fly, while the Box and Canopy traps require that the horse fly enter the trap from below. Moreover, different horse fly species have unique feeding behaviours and patterns (Krčmar \& Galić, 2004). Box traps, given their particular design and construction, may be better suited for catching species that feed on the ventral side of the prey.

Control of insect populations, particularly those that are considered pests, is generally difficult concerning the reduction of their populations (Barros \& Foil, 2007). Horse flies are not the exception, and their control must be based on protective measures against adults (Foil \& Hogsette, 1994). While it is evident that traps can not guarantee the overall population decline of any horse fly species, their use is recommended as a tool to eliminate excessive numbers of pests locally and thus reduce the impact of pests on domestic animals (Baldacchino et al., 2014a). Our study showed that Box traps are best suited for such tasks concerning the numbers of horse flies caught and their relative trapping efficiency. This result was consistent regarding both the overall number of captured horse flies and the most abundant species in the area.

ACKNOWLEDGEMENTS. This study was supported by the Ministry of Science, Education and Sport of the Republic Croatia (research grant number: 285-0731674-2200). Authors wish to thank S. Krčmar for his help in this research.

\section{REFERENCES}

Baldacchino F., Cadier J., Porciani A., Buatois B., Dormont L. \& JAY-RoBert P. 2013: Behavioural and electrophysiological responses of females of two species of tabanid to volatiles in urine of different mammals. - Med. Vet. Entomol. 27: 77-85.

Baldacchino F., Desquesnes M., Mihok S., Foil L.D., Duvallet G. \& JitTAPALAPONG S. 2014a: Tabanids: Neglected subjects of research, but important vectors of disease agents! - Infect. Genet. Evol. 28: 596-615.

Baldacchino F., Gardès L., De Stordeur E., Jay-Robert P. \& Garros C. 2014b: Blood-feeding patterns of horse flies in the French Pyrenees. - Vet. Parasitol. 199: 283-288.

Barros A. \& FoIL L. 2007: The influence of distance on movement of tabanids (Diptera: Tabanidae) between horses. - Vet. Parasitol. 144: 380-384.

Blahó M., Egri Á., Barta A., Antoni G., Kriska G. \& Horváth G. 2012: How can horseflies be captured by solar panels? A new concept of tabanid traps using light polarization and electricity produced by photovoltaics. - Vet. Parasitol. 189: 353-365.

Chvála M. 1988: Family Tabanidae. In Soós Á. (ed.): Catalogue of Palaearctic Diptera. Akadémiai Kiadó, Budapest, pp. 97171.

Chvála M., Lyneborg L. \& Moucha J. 1972: The Horse Flies of Europe (Diptera, Tabanidae). Entomological Society of Copenhagen, Copenhagen, 500 pp.

Chvála M., Ježek J. \& Nilsson A. 1997: Diptera Tabanidae, Horse Flies. In Nilsson A. (ed.): The Aquatic Insects of North Europe. Apollo Boks, Stenstrup, pp. 295-309.

Desquesnes M., Biteau-Coroller F., Bouyer J., Dia M.L. \& Foil L. 2009: Development of a mathematical model for mechani- 
cal transmission of trypanosomes and other pathogens of cattle transmitted by tabanids. - Int. J. Parasitol. 39: 333-346.

Dodds K.J., Allison J.D., Miller D.R., Hanavan R.P. \& Sweeney J. 2015: Considering species richness and rarity when selecting optimal survey traps: comparisons of semiochemical baited flight intercept traps for Cerambycidae in eastern North America. - Agric. For. Entomol. 17: 36-47.

Egri Á., Blahó M., Sándor A., Kriska G., Gyurkovszky M., FARKAS R. \& HoRvÁth G. 2012: New kind of polarotaxis governed by degree of polarization: attraction of tabanid flies to differently polarizing host animals and water surfaces. Naturwissenschaften 99: 407-416.

Foll L. \& HogsetTe J. 1994: Biology and control of tabanids, stable flies and horn flies. - Rev. Sci. Tech. OIE 13: 1125-1158.

GiBSON G. \& TORR S. 1999: Visual and olfactory responses of haematophagous Diptera to host stimuli. - Med. Vet. Entomol. 13: 2-23.

Hall M.J., FARKas R. \& ChaINEy J.E. 1998: Use of odour-baited sticky boards to trap tabanid flies and investigate repellents. Med. Vet. Entomol. 12: 241-245.

Hansens E. \& Race S. 2011: Rutgers, School of Environmental and Biological Sciences. URL: http://www.rci.rutgers. edu/ insects/greenheads.htm (last accesed 19 Jan. 2011).

Horváth G., Majer J., Horváth L., Szivák I. \& Kriska G. 2008 Ventral polarization vision in tabanids: horseflies and deerflies (Diptera: Tabanidae) are attracted to horizontally polarized light. - Naturwissenschaften 95: 1093-1100.

Hribar L., Leprince D. \& Foil L. 1991: Design for a canopy trap for collecting horse flies (Diptera: Tabanidae). - J. Am. Mosq. Contr. Assoc. 7: 657-659.

KRČMAR S. 2005: Response of horse flies (Diptera, Tabanidae) to different olfactory attractants. - Biologia (Bratislava) $\mathbf{6 0}$ : 611-613.

KrČMar S. \& Galić B. 2004: Statistical analysis of the feeding sites for some horse flies (Diptera: Tabanidae) on horses in Eastern Croatia. - Ekologia (Bratislava) 23: 321-327.

KRČMAR S. \& RUPNIK POKLUKAR D. 2011: Comparison of the efficiency of three types of Canopy traps on the collection of horse flies (Diptera: Tabanidae). - Entomol. Gener. 33: 115-123.

KrČMar S., MikuŠKa A. \& Merdić E. 2006: Response of Tabanidae (Diptera) to different natural attractants. - J. Vector Ecol. 31: $262-265$.

KrČMAR S., MiKuŠKa A. \& JASIKA M. 2009: Horsefly fauna of three different forest communities in the Danube river floodplain in Croatia (Diptera: Tabanidae). - Entomol. Gener. 32 23-34.
KrČMar S., MikuŠKa A. \& Radolić V. 2010: Comparison of sampling tabanids (Diptera: Tabanidae) by four different potential attractants. - J. Appl. Entomol. 134: 608-613.

KrČMar S., Radolić V., LaJoš P. \& LuKaČević I. 2014: Efficiency of colored modified box traps for sampling of tabanids. Parasite 21: 67.

KREBS S.J. 1989. Ecological Methodology. Harper Collins, New York, $652 \mathrm{pp}$.

Mazokhin-Porshnyakov G.A., Cherkosov A.D., Burakova A. \& VISCHNEVSKAYA T.M. 1975: On the color vision of Tabanidae (Diptera). - Zool. Zh. 54: 574-576.

Minok S., Carlson D., Krafsur E. \& Foll L. 2006: Performance of the Nzi and other traps for biting flies in North America. Bull. Entomol. Res. 96: 387-397.

MıноK S. 2007: Nzi Trap Website. URL: http://www.nzitrap.com (last accesed 15 Apr. 2011).

MinoK S. \& CARLSON D. 2007: Performance of painted plywood and cloth Nzi traps relative to Manitoba and Greenhead traps for tabanids and stabile flies. - J. Econ. Entomol. 100: 613618.

MiKuŠKa A. 2010: Ecology of Horse Flies (Tabanidae) in the Croatian Podunavlje Floodplain and Efficiency of Attractants in the Control of their Abundance. PhD thesis, Faculty of Science, University of Zagreb, Zagreb, vi + 164 pp.

Muzari M., Jones R., Skerratt L. \& Duran T. 2010: Feeding success and trappability of horse flies evaluated with electrocuting nets and odour-baited traps. - Vet. Parasitol. 171: 321-326.

Roskov Y., Kunze T., Paglinawan L., Orrell T., Nicolson D., Culham A., Bailly N., Kirk P., Bourgoin T. \& Baillargeon G. 2015: Species 2000 \& ITIS Catalogue of Life. URL: http:// catalogueoflife.org/annual-checklist/2015 (last accesed 17 Jul. 2015).

TAYLOR D.B. \& Berkebile D. 2006: Comparative efficiency of six stable fly (Diptera: Muscidae) traps. - J. Econ. Entomol. 99: 1415-1419.

Van Hennekeler K., Jones R., Skerratt L., Fitzpatrick L., Reid S. \& Bellis G. 2008: A comparison of trapping methods for Tabanidae (Diptera) in North Queensland, Australia. - Med. Vet. Entomol. 22: 26-31.

VotÝpKa J., RÁdrová J., SkalickÝ T., JirkŮ M., Jirsová D., Minalca A.D., D’Amico G., Petrželková K.J., Modrý D. \& LUKEŠ J. 2015: A tsetse and tabanid fly survey of African great apes habitats reveals the presence of a novel trypanosome lineage but the absence of Trypanosoma brucei. - Int. J. Parasitol. 45: 741-748.

Received June 2, 2016; revised and accepted October 7, 2016 Published online October 31, 2016 